\title{
BMJ
}

\section{Effect of accelerated rehabilitation on function after ankle sprain: randomised controlled trial}

\author{
Chris M Bleakley, research associate, ${ }^{1}$ Seán R O'Connor, research assistant, ${ }^{1}$ Mark A Tully, research fellow, ${ }^{2}$ \\ Laurence G Rocke, consultant in emergency medicine, ${ }^{3}$ Domhnall C MacAuley, visiting professor of health \\ sciences, ${ }^{1}$ lan Bradbury, assistant director of statistics, ${ }^{4}$ Stephen Keegan, statistician, ${ }^{4}$ Suzanne M \\ McDonough, professor of health and rehabilitation sciences ${ }^{1}$
}

${ }^{1}$ Health and Rehabilitation Sciences Research Institute, School of Health Sciences, University of Ulster, Jordanstown, Newtownabbey, Co Antrim BT37 OQB

${ }^{2}$ UKCRC Centre of Excellence for Public Health (NI), Queen's

University Belfast, Royal Victoria Hospital, Belfast

${ }^{3}$ Department of Emergency Medicine, Royal Victoria Hospital, Belfast

${ }^{4}$ Frontier Science (Scotland), Kincraig, Inverness-shire

Correspondence to: C M Bleakley chrisbleakley@hotmail.com

Cite this as: BMJ 2010;340:c1964 doi:10.1136/bmj.c1964

\section{ABSTRACT}

Objective To compare an accelerated intervention incorporating early therapeutic exercise after acute ankle sprains with a standard protection, rest, ice, compression, and elevation intervention.

Design Randomised controlled trial with blinded outcome assessor.

Setting Accident and emergency department and university based sports injury clinic.

Participants 101 patients with an acute grade 1 or 2 ankle sprain.

Interventions Participants were randomised to an accelerated intervention with early therapeutic exercise (exercise group) or a standard protection, rest, ice, compression, and elevation intervention (standard group).

Main outcome measures The primary outcome was subjective ankle function (lower extremity functional scale). Secondary outcomes were pain at rest and on activity, swelling, and physical activity at baseline and at one, two, three, and four weeks after injury. Ankle function and rate of reinjury were assessed at 16 weeks. Results An overall treatment effect was in favour of the exercise group $(\mathrm{P}=0.0077)$; this was significant at both week 1 (baseline adjusted difference in treatment 5.28, 98.75\% confidence interval 0.31 to $10.26 ; P=0.008$ ) and week 2 (4.92, 0.27 to 9.57; $P=0.0083)$. Activity level was significantly higher in the exercise group as measured by time spent walking (1.2 hours, 95\% confidence interval 0.9 to $1.4 v 1.6,1.3$ to 1.9 ), step count (5621 steps, $95 \%$ confidence interval 4399 to $6843 v 7886,6357$ to 9416 ), and time spent in light intensity activity ( 53 minutes, $95 \%$ confidence interval 44 to $60 v 76,58$ to 95). The groups did not differ at any other time point for pain at rest, pain on activity, or swelling. The reinjury rate was $4 \%$ (two in each group).

Conclusion An accelerated exercise protocol during the first week after ankle sprain improved ankle function; the group receiving this intervention was more active during that week than the group receiving standard care.

Trial registration Current Controlled Trials ISRCTN13903946.

\section{INTRODUCTION}

Ankle sprains are one of the most common musculoskeletal injuries. An estimated 5000 new cases occur each day in the United Kingdom, ${ }^{1}$ with about 302000 annual admissions to accident and emergency departments. ${ }^{2}$ In the acute phase, ankle sprains are associated with pain and loss of function, and one quarter of injured people are unable to attend school or work for more than seven days ${ }^{1}$; long term risks include reinjury or residual problems. ${ }^{3-5}$ In a recent systematic review, ${ }^{6}$ the proportion of patients with full recovery in three years ranged from just 36\% to $85 \%$. The annual cost associated with ankle sprains in the Netherlands alone is estimated at around $€ 84 \mathrm{~m}$ $(£ 73 \mathrm{~m} ; \$ 113 \mathrm{~m})^{7}$

The optimal treatment for ankle sprains remains uncertain. Protection, rest, ice, compression, and elevation, synonymous with management of acute soft tissue injury, suggests a passive approach to treatment. Many accident and emergency departments favour non-weight bearing using crutches, with others favouring rest and immobilisation with a cast, for up to two weeks. $^{8-11}$

Animal models ${ }^{12-14}$ describe a range of biochemical and physiological mechanisms that support the use of early active mobilisation after soft tissue injury. Metaanalyses also conclude that functional treatments may be the most effective approach, ${ }^{15-18}$ using early mobilisation and weight bearing, with adjunct treatments that include external supports, compression bandages, ice (cryotherapy), non-steroidal anti-inflammatory drugs, and therapeutic exercise. ${ }^{619}$ The purpose of rehabilitation exercise is to improve muscle strength, range of movement, and sensorimotor control, which are commonly impaired after ankle sprain. ${ }^{20-23}$ We compared an accelerated protocol for functional rehabilitation with the current best treatment for improving recovery from ankle sprain.

\section{METHODS}

We carried out a randomised controlled trial following the published protocol. ${ }^{24}$ Patients aged 16-65 years attending an accident and emergency department 
(Royal Victoria Hospital, Belfast) or sports injury clinic (University of Ulster) were included if they had an acute $(<7$ days) grade 1 or 2 ankle sprain. Two researchers (CMB, SRO'C) excluded patients if they had a complete (grade 3) rupture of the ankle ligament (mechanical instability diagnosed by a positive anterior drawer or inversion stress test), ${ }^{25}$ had a bony ankle injury (indicated by Ottawa ankle rules ${ }^{26}$ or plain $\mathrm{x}$ ray films), had multiple injuries (for example, other joint injury or fracture), had a contraindication to cryotherapy, were non-English speaking, were under the influence of drugs or alcohol, or had an insufficient address for follow-up. Participants signed a letter of informed consent.

\section{Treatment (baseline to week 1)}

Both groups received written advice on applying ice and compression. Such treatment followed a standard intermittent protocol ${ }^{27}$ and consisted of two 10 minute applications of ice and compression interspersed with 10 minutes of rest (repeated three times daily for one week). In week 1 the exercise group undertook therapeutic exercises adapted from a standard protocol (see web extra). ${ }^{28}$ The group received standardised verbal and written instructions and a DVD showing the exercises.

To monitor compliance with treatment and analgesic use participants completed a treatment diary, which was returned to the research physiotherapists (SRO'C, $\mathrm{CMB}$ ) at the first follow-up (week 1). External ankle support (including forms of taping, bracing, and bandaging) or analgesics were not routinely provided.

\section{Standardised treatment (weeks 1-4)}

Treatment was standardised in both groups from weeks 1-4 and consisted of ankle rehabilitation exercises focusing on muscle strengthening, neuromuscular training, and sports specific functional exercises. The participants undertook these exercises for 30 minutes each week, once under supervision from the research physiotherapist and four times as a home based treatment.

\section{Outcome measurements}

A researcher (MAT) blinded to the intervention group recorded outcomes at weeks 1-4.

The primary outcome measure was subjective ankle function, assessed using the lower extremity functional scale. ${ }^{29}$ This scale is a self completed questionnaire comprising 20 functional leg activities, each scored on a five point scale ( 0 impossible, 4 no difficulty), giving a maximum score of 80 . The secondary outcome measures included pain at rest and with activity, assessed using a $10 \mathrm{~cm}$ visual analogue scale ${ }^{30}$; swelling, using a modified version of the figure of eight method $^{31}$; and physical activity, using a professional physical activity logger (activPAL; PAL technologies, Glasgow). ${ }^{32}$ The sports ankle rating score ${ }^{33}$ was completed at baseline and on completion of the study. This scale includes an objective assessment of gait, joint range of movement, strength, mechanical stability, postural stability, and a functional, single leg hop test. Self reported function was also assessed using the Karlsson score ${ }^{34}$ at baseline, on completion of the study, and at the 16 week follow-up. Reinjury rates were recorded during follow-up assessments at weeks $1-4$ and at week 16 ( see web extra for details of outcome measures).

\section{Statistical analysis}

We determined sample size ${ }^{35}$ on the basis of our previous work. ${ }^{27}$ We estimated that there would be a $10 \%$ attrition rate and thus aimed to recruit 60 participants in each group (assuming 80\% power and an $\alpha$ of 0.05 ), using a clinically important change of 9 points in the primary outcome measure, with a standard deviation of $16 .{ }^{29} \mathrm{We}$ used a computer generated randomisation sequence to randomise participants. Group allocation was printed on a card (group 1 for standard care group, group 2 for exercise group), and placed in sequentially numbered opaque envelopes with carbon paper on top $(\mathrm{SMcD})$. Randomisation was stratified according to athletic or non-athletic background. For each stratum we produced separate block randomisation sequences using an allocation ratio of 1:1 and a block size of 4 . After written consent had been obtained and baseline assessment, SRO'C and CMB randomised participants to one of the two groups from the numbered envelopes.

A constrained (as the trial is randomised we constrained the baseline means to equality) linear mixed model analysis ${ }^{36}$ was undertaken based on intention to treat, using response variables of lower extremity functional scale score, pain at rest, pain on activity, and swelling, and covariates of treatment type (standard or exercise), time, and athletic background (athletic or non-athletic). We calculated the difference between treatments (adjusted for baseline values) along with 98.75 confidence intervals at each time point (weeks 1-4). The level of significance was set at a Bonferroni corrected level of $0.0125(0.05 / 4)$.

We also assessed missing data by repeating the linear mixed model analyses with imputation using last observation carried forward. We also compared dropouts with non-dropouts for baseline scores, scores at the week preceding dropout from the trial (lower extremity functional scale, pain at rest, pain on activity, and swelling), and the change in score between baseline and week 1 (lower extremity functional scale only).

\section{RESULTS}

Between July 2007 and August 2008, 212 patients were assessed for eligibility. In total, 101 met the inclusion criteria and were randomised to either the standard group $(\mathrm{n}=51)$ or the exercise group $(\mathrm{n}=50)$. One participant in the standard group did not receive the intervention as allocated. Fifteen participants dropped out during the trial. Figure 1 summarises the recruitment, randomisation, and follow-up. ${ }^{37}$ Table 1 summarises the baseline personal and prognostic characteristics of the participants and table 2 the primary and secondary outcomes. 


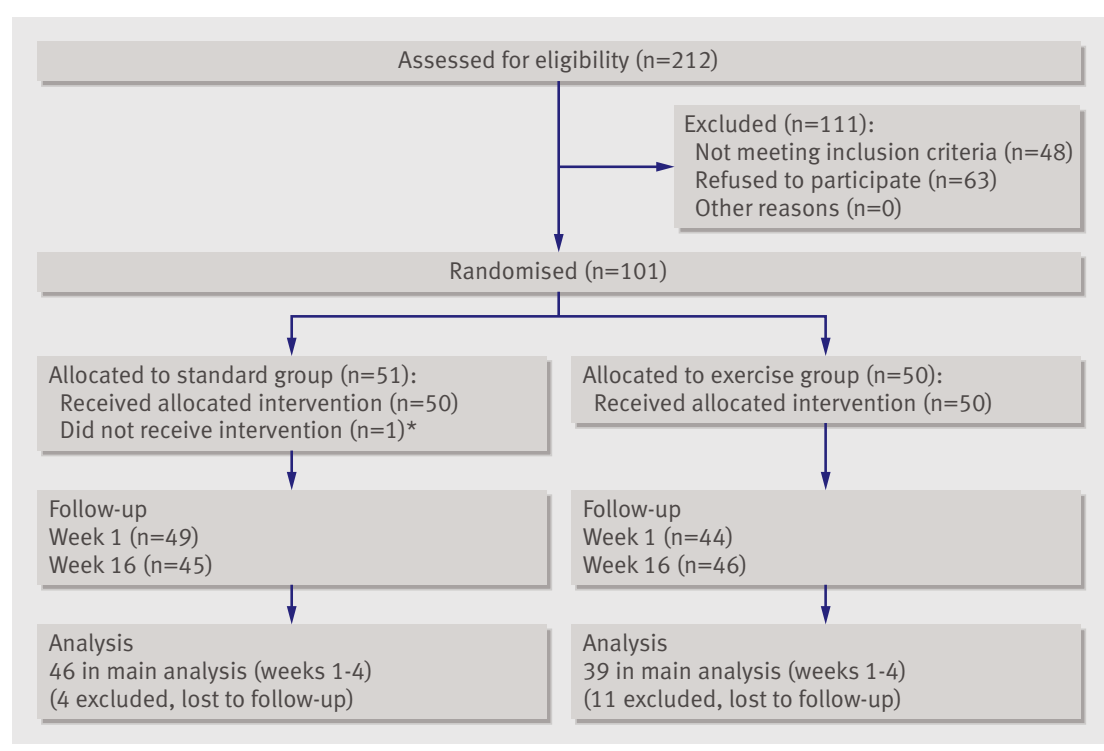

Fig 1| Flow of participants through trial. *Excluded after randomisation (not included in main analysis)

Function, pain, and swelling

Figure 2 highlights the mean (95\% confidence intervals) functional scores from baseline to week 4 . On average, participants in the exercise group did better at each time point for function, and the overall treatment effect was in favour of the exercise group $(\mathrm{P}=0.0077$; fig 3). A significant effect was in favour of the exercise group at both week 1 (baseline adjusted difference in treatment $5.28,0.31$ to $10.26 ; \mathrm{P}=0.008$ ) and week 2 (4.92, 0.27 to $9.57 ; \mathrm{P}=0.0083$; fig 3$)$. No overall treatment effect was observed for pain at rest $(\mathrm{P}=0.1558)$, pain with activity $(\mathrm{P}=0.3514$; fig 4$)$, or swelling $(\mathrm{P}=0.6478)$.

Table 1|Baseline comparison of personal and prognostic factors. Values are means (standard deviations) unless stated otherwise

\begin{tabular}{|c|c|c|}
\hline Characteristics & $\begin{array}{l}\text { Standard group } \\
\quad(n=51)\end{array}$ & $\begin{array}{l}\text { Exercise group } \\
\quad(n=50)\end{array}$ \\
\hline Age (years) & $26.6(7.5)$ & $25.3(8.3)$ \\
\hline Height (cm) & $176.1(5.94)$ & $174.6(6.27)$ \\
\hline Body weight (kg) & $78.6(7.94)$ & $77.8(8.21)$ \\
\hline No of men/women & $34 / 17$ & $35 / 15$ \\
\hline No athletic/non-athletic & $31 / 20$ & $31 / 19$ \\
\hline No with/without previous ankle injury & $20 / 31$ & $23 / 27$ \\
\hline No with/without chronic ankle instability ${ }^{38}$ & $6 / 45$ & $9 / 41$ \\
\hline Limb dominance (left/right) & $10 / 41$ & $18 / 32$ \\
\hline Injured limb (left/right) & $28 / 23$ & $31 / 19$ \\
\hline Time since injury (hours) & $57.3(29.8)$ & $49.7(32.5)$ \\
\hline Mechanism of injury (inversion/eversion/from landing/unknown) & $41 / 1 / 7 / 2$ & $37 / 3 / 4 / 6$ \\
\hline Cause (sport/work/other) & $34 / 12 / 5$ & $34 / 5 / 11$ \\
\hline Grade (1 or 2$)$ & $18 / 33$ & $11 / 39$ \\
\hline Baseline lower extremity functional scale score ${ }^{29}$ & $35.8(17.38)$ & $36.2(19.04)$ \\
\hline Baseline SARS score (objective) (0-60) & $31.7(13.22)$ & $29.5(15.3)$ \\
\hline \multicolumn{3}{|c|}{$\begin{array}{l}\text { SARS= sports ankle rating instability. }{ }^{33} \\
\text { *Self reported measure of function using pain, instability, swelling, stiffness, functional activity, and need for } \text { support. }^{34}\end{array}$} \\
\hline
\end{tabular}

An analysis after imputation (last observation carried forward) concurred with the main intention to treat analysis. Dropouts $(\mathrm{n}=15)$ and non-dropouts $(\mathrm{n}=85)$ had similar baseline scores $(\mathrm{P}=0.61)$, change in scores on the lower extremity functional scale between baseline and week $1(\mathrm{P}=0.095)$, and scores recorded the week preceding dropout.

\section{Physical activity (week 1 after injury)}

Data on physical activity were available for the first week after injury in 34 participants (16 standard group, 18 exercise group) who were provided with an activity monitor. The exercise group were significantly more active, as measured by time spent walking $(\mathrm{P}=0.029$; table 3$)$, the average number of steps taken daily $(\mathrm{P}=0.021$; table 3$)$, and the time spent in light intensity activities $(\mathrm{P}=0.047$; table 3$)$.

\section{Adverse events}

During the first four weeks of follow-up no incidences of skin burns or nerve palsies were recorded and no reinjuries reported.

\section{6 week follow-up}

Both groups recorded high Karlsson scores at 16 weeks (standard: mean 98.4 (SD 2.81); exercise: mean 97.31 (SD 4.89)), with no differences between groups. Four reinjuries were reported (two in each group).

\section{DISCUSSION}

This randomised controlled trial showed that an accelerated functional treatment, incorporating therapeutic exercises during the first week after ankle sprain, produced significant improvements to short term ankle function compared with standard treatment. The exercise group had greater weightbearing mobilisation at one week. Both groups had good ankle function at the 16 week follow-up, with just four reinjuries.

\section{Functional treatment of ankle sprain}

Ankle sprains are often regarded as minor injuries but they cause short term immobility and loss of function, with a risk of long term problems and reinjury. Anecdote based treatment may be one reason for poor prognosis. The first clinical question in the early

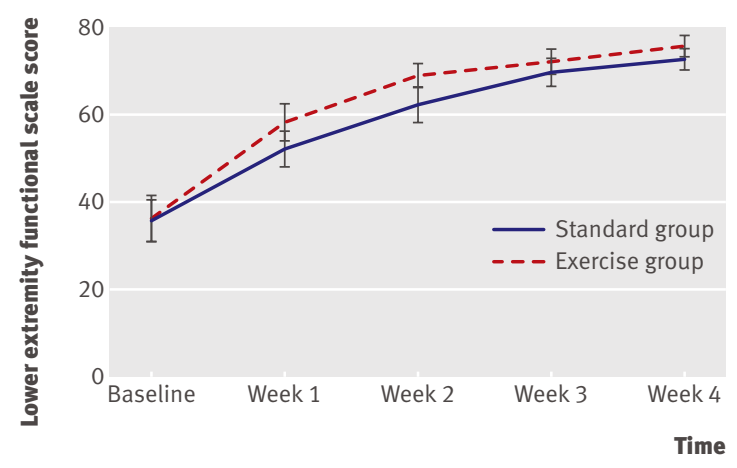

Fig 2 Mean lower extremity functional scale scores from baseline to week 4 . Whiskers are $95 \%$ confidence intervals 
Table 2 Summary of primary and secondary outcomes. Values are means (standard deviations; $95 \%$ confidence intervals) unless stated otherwise

\begin{tabular}{lcc}
$\begin{array}{l}\text { Variables } \\
\text { Baseline: }\end{array}$ & Standard group $(\mathrm{n}=51)$ & Exercise group $(\mathrm{n}=50)$ \\
\hline Lower extremity functional scale score $(0-80)$ & $\begin{array}{c}35.8(17.38 ; 30.8 \text { to } \\
40.7)\end{array}$ & $\begin{array}{c}36.2(19.04 ; 30.8 \text { to } \\
41.6)\end{array}$ \\
\hline Pain at rest $(0-100)$ & $25.8(23.3 ; 19.3$ to 32.4$)$ & $\begin{array}{c}22.7(22.87 ; 16.2 \text { to } \\
29.2)\end{array}$ \\
\hline Pain on activity $(0-100)$ & $54.0(24.06 ; 47.2$ to & $\begin{array}{c}57.5(25.11 ; 50.4 \text { to } \\
64.7)\end{array}$ \\
\hline Swelling $(\mathrm{cm})$ & $1.9(1.86 ; 1.3$ to 2.5$)$ & $2.0(1.9 ; 1.4$ to 2.6$)$ \\
\hline Sports ankle rating system (objective) $(0-60)$ & $31.7(13.22 ; 0$ to 54$)$ & $29.5(15.3 ; 2$ to 54$)$ \\
\hline Karlsson score* $(0-100)$ & $50.31(19.6 ; 15$ to 95$)$ & $45.48(21.8 ; 0$ to 85$)$ \\
\hline Adherence: & & \\
\hline Self reported adherence week $1(\%) \dagger$ & $77.9(14.4 ; 42$ to 100$)$ & $67.8(16.2 ; 42$ to 100$)$ \\
\hline
\end{tabular}

\section{Follow-up}

Week 1:

\begin{tabular}{lcc}
\hline Lower extremity functional scale & $52.1(14.7 ; 47.8$ to 56.3$)$ & $57.9(14.4 ; 53.5$ to 62.3$)$ \\
\hline Pain at rest & $10.3(13.0 ; 6.5$ to 14.0$)$ & $6.2(7.85 ; 3.8$ to 8.6$)$ \\
\hline Pain on activity & $33.5(19.9 ; 27.8$ to 39.3$)$ & $28.9(23.5 ; 21.8$ to 36.1$)$ \\
\hline Swelling & $1.0(1.5 ; 0.5$ to 1.5$)$ & $1.0(1.3 ; 0.5$ to 1.4$)$ \\
\hline Week 2: & & \\
\hline Lower extremity functional scale & $61.8(13.3 ; 57.7$ to 65.9$)$ & $68.6(8.8 ; 65.8$ to 71.4$)$ \\
\hline Pain at rest & $5.9(11.0 ; 2.5$ to 9.3$)$ & $3.6(5.8 ; 1.7$ to 5.5$)$ \\
\hline Pain on activity & $18.7(14.4 ; 14.2$ to 23.1$)$ & $20.1(20.1 ; 13.6$ to 26.6$)$ \\
\hline Swelling & $0.6(0.8 ; 0.3$ to 0.9$)$ & $0.7(1.0 ; 0.2$ to 1.1$)$ \\
\hline Week 3: & & \\
\hline Lower extremity functional scale & $69.1(10.4 ; 65.9$ to 72.4$)$ & $71.5(8.6 ; 68.6$ to 74.5$)$ \\
\hline Pain at rest & $3.1(5.8 ; 1.3$ to 5.0$)$ & $2(4.1 ; 0.5$ to 3.4$)$ \\
\hline Pain on activity & $11.9(11.2 ; 8.4$ to 15.5$)$ & $12.3(15.4 ; 7.0$ to 17.6$)$ \\
\hline Swelling & $1.0(0.9 ; 0.6$ to 1.4$)$ & $0.8(0.7 ; 0.4$ to 1.1$)$ \\
\hline Week 4: & & \\
\hline Lower extremity functional scale & $71.9(8.0 ; 69.4$ to 74.3$)$ & $74.9(7.0 ; 72.4$ to 77.5$)$ \\
\hline Pain at rest & $1.7(3.2 ; 0.8$ to 2.7$)$ & $1.9(6.44 ;-0.5$ to 4.3$)$ \\
\hline Pain on activity & $8.9(12.8 ; 4.9$ to 12.8$)$ & $9.5(15.4 ; 3.9$ to 15.2$)$ \\
\hline Swelling & $0.7(1.3 ; 0.1$ to 1.2$)$ & $0.4(1.0 ;-0.1$ to 0.9$)$ \\
\hline Mean (SD) sports ankle rating system (objective) $(0-60)$ & $58.8(2.6)$ & $56.9(2.7)$ \\
\hline Mean (SD) Karlsson score (0-100) & $95.2(4.4)$ & $90.4(5.1)$ \\
\hline Week 16 & $98.4(2.81)$ & $97.3(4.89)$ \\
\hline Mean (SD) Karlsson score* (0-100) & 2 & 2 \\
\hline Total No of reinjuries & & \\
\hline
\end{tabular}

*Self reported measure of function using pain, instability, swelling, stiffness, functional activity, and need for support.

$\dagger 100 \%$ compliance=three treatments per day for first week.

management of ankle sprain is whether to mobilise or not. Recent surveys of accident and emergency departments show a range of strategies, from discharge with immediate weight bearing to immobilisation with a cast and non-weight bearing. ${ }^{8-11}$ Systematic reviews support functional treatment, compared with surgery or immobilisation, particularly for mild to moderate sprains. ${ }^{1518}$ Clinically, however, functional treatment has many variations, but few are based on clinical trials. External supports such as elastic bandaging, taping, and semirigid braces are often used to facilitate early controlled mobilisation and weight bearing. But both the clinical and the cost effectiveness of elastic tubigrip bandaging is questioned. ${ }^{39}$ One systematic review found preliminary evidence that lace-up supports

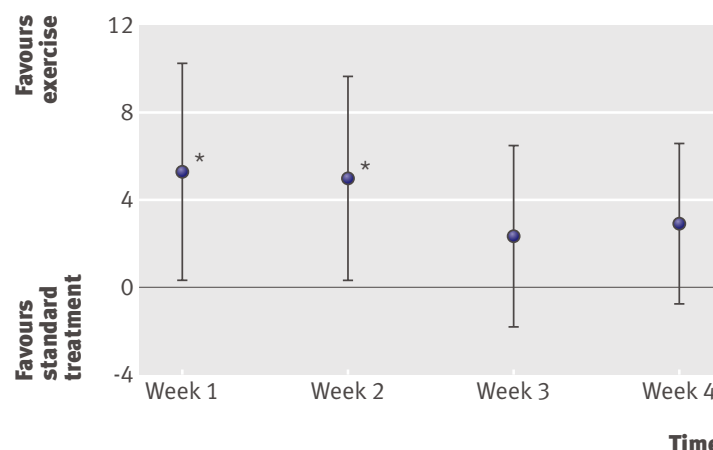

Fig $3 \mid$ Difference in treatment after adjustment for lower extremity functional scale scores, weeks 1 to 4 . Dots are point estimates for difference and whiskers are $98.75 \%$ confidence intervals. *Difference in treatment adjusted for baseline values, $\mathrm{P}<0.0125$

may be the most effective form of external support, although few definite conclusions were reached. ${ }^{16}$

\section{Rehabilitation exercise}

Various rehabilitation exercises are used as an adjunct to functional treatment, much of which is based on Freeman' ${ }^{40}$ concept that joint injury can result in proprioceptive deficits that hinder functional recovery, and risk longer term ankle instability. Contemporary research shows that ankle trauma results in alterations to joint positional sense, ${ }^{41}$ balance,${ }^{20}$ muscle activation, ${ }^{23}$ kinematics, ${ }^{21}$ and neuromuscular patterns. ${ }^{22}$ A recent systematic review found only two small, randomised controlled studies of ankle rehabilitation together with functional treatment for acute ankle sprain. ${ }^{424}$ They found evidence that wobble board training ${ }^{42}$ and a strength and balance training programme $^{43}$ initiated in the first week after sprain, decreased pain and reinjury compared with control groups given advice on ice, compression, and elevation. These studies had a different intervention and outcome measurement to our trial, and both studies had methodological limitations, including lack of allocation concealment, assessor blinding, intention to treat, and a high dropout rate. In our current study we used an exercise group that initiated rehabilitation exercises during the first week of injury. The exercises were prescribed for 20 minutes, three times a day, and focused on increasing ankle range of movement, activation and strengthening of ankle musculature, and restoring normal sensorimotor control. The treatment was successful, with no adverse side effects, and resulted in significantly higher levels of short term subjective function and increased weightbearing mobilisation. This may provide further guidance for clinicians when considering the optimal dosage and nature of exercise prescription after acute ankle injury.

Early return to normal lower limb function is a key objective of functional treatment. Our findings provide evidence that rehabilitation exercises are an effective adjunct to functional treatment of ankle sprains. There are several possible reasons for their effectiveness. 


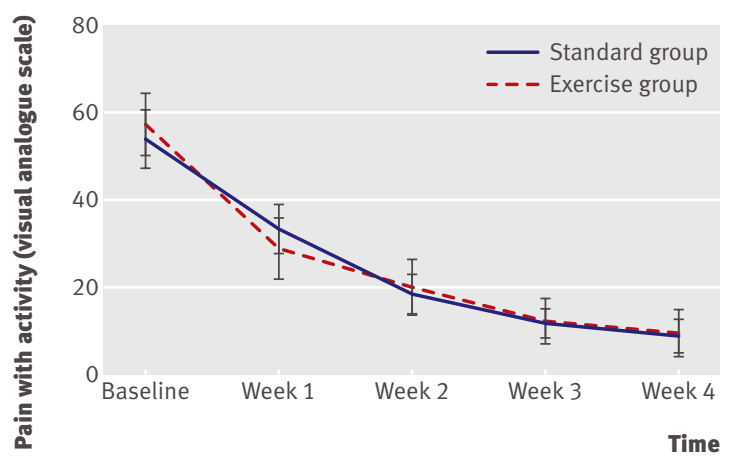

Fig 4 Mean values for pain with activity from baseline to week 4 . Whiskers are $95 \%$ confidence intervals

After a traumatic sprain injury, ankle function can be hindered by pain and swelling. Indeed, it is well documented that a painful, distended joint can cause a reflex inhibition of the surrounding ankle musculature, known as arthrogenic muscle inhibition. Arthrogenic muscle inhibition has been observed in acutely injured ankles ${ }^{23}$ and knees $^{44}$ and even in patients with chronic ankle problems. ${ }^{45}$ In the acute phases of injury, arthrogenic muscle inhibition has a clear influence on neuromuscular activation patterns, ${ }^{46}$ muscle strength, ${ }^{47}$ and balance, ${ }^{48}$ and subsequently a patient's ability to fully mobilise and weight bear. The main aim of initiating the exercise intervention during the acute phases of injury was to initiate early (re)activation of ankle musculature and functional movement patterns. This approach had a direct impact on functional status in our study; however, future work is required to confirm the pathophysiological mechanism-for example, decreased impact of arthrogenic muscle inhibition in the early stages of injury.

\section{Reinjury}

A major concern with functional treatment of ankle sprain is the risk of delaying soft tissue recovery, or reinjury. Our exercise intervention during week 1 put no adverse stress over the lateral joint structures and aside from controlled circumduction movements, all other exercises were in the saggital plane or used static muscle activation. Four reinjuries occurred, all between 12 and 16 weeks after injury and during sporting activity. Two reinjuries occurred in each group, which is low compared with other studies, which had

Table $3 \mid$ Time spent in activities during first week after ankle sprain. Values are means $(95 \%$ confidence intervals) unless stated otherwise

\begin{tabular}{lccc} 
Variables & Standard group $(\mathrm{n}=16)$ & Exercise group $(\mathrm{n}=18)$ & P value \\
\hline Sitting (h/day) & $19.8(19$ to 20.5$)$ & $18.3(18.1$ to 19.5$)$ & 0.06 \\
\hline Standing (h/day) & $3.1(2.5$ to 3.6$)$ & $3.3(2.9$ to 3.8$)$ & 0.4 \\
\hline Walking (h/day) & $1.2(0.9$ to 1.4$)$ & $1.6(1.3$ to 1.9$)$ & 0.029 \\
\hline Step count (No/day) & $5621(4399$ to 6843$)$ & $7886(6357$ to 9416$)$ & 0.021 \\
\hline Activity level: & $53(44$ to 60$)$ & & \\
\hline Light & $14.5(8.4$ to 20.5$)$ & $76.2(58$ to 95$)$ & 0.047 \\
\hline Moderate & $0.07(0.02$ to 0.12$)$ & $0.62(0.14$ to 1.1$)$ & 0.1 \\
\hline High & & 0.23 \\
\hline
\end{tabular}

rates as high as $34-42 \%{ }^{6}$ One reason for our low reinjury rate might be that both groups had a standardised, physiotherapy led, rehabilitation programme from week 1 that included strengthening, stretching, and neuromuscular training, and, if appropriate, sports specific training between weeks 2 and 4 after injury. Referral to physiotherapy is, however, not standard practice within accident and emergency departments ${ }^{8}$ and may limit the generalisability of our reinjury figures.

\section{Weightbearing mobilisation}

To our knowledge this is the first trial to record objectively weightbearing mobilisation after an acute soft tissue injury of the ankle. All participants undertook progressive weightbearing mobilisation during the first week, with most activity in the exercise group. Perhaps, surprisingly, participants spent an average of between 1.2 hours (standard group) and 1.6 hours (exercise group) walking each day during the first week after injury. Most of this walking was undertaken at a light intensity. It is not clear how closely this relates to the participants' normal levels of physical activity and walking, however, but these data help indicate the levels of activity that can be safely achieved as part of functional management of ankle sprains.

Early return to normal function has many clinical and economic benefits. Few people seem to achieve this goal, however, and an estimated $25 \%$ of those with ankle sprain are absent from work or school for more than one week, ${ }^{1}$ and $80 \%$ of the annual cost of ankle sprain is due to time lost from work. ${ }^{7}$ Most ankle injuries are managed at accident and emergency departments, and treatment varies with many favouring immobilisation for seven to 10 days. ${ }^{49}$ An earlier return to work might be expected with functional treatment. We found that mobility is safely maintained after mild and moderate ankle sprains.

\section{Limitations of the study}

Our study has some potential limitations. Although we did not achieve our target sample size we were still able to show significant improvements in our primary outcome. We did not, however, have sufficient power to show a difference in the secondary outcomes and, overall, the dropout rate was higher in the exercise group. One participant from the standard group was excluded after randomisation when follow-up radiography revealed a fracture. Owing to ethical considerations this participant was excluded from the analysis. As the participant did not actually start treatment, and the reascertainment of eligibility was the same in both treatment arms, we thought it unlikely that exclusion would lead to bias. While our study showed benefits in mild to moderate ankle sprains, further studies would be required to show if this accelerated approach to rehabilitation is safe and effective in more severe ankle sprains. One study ${ }^{50}$ showed improved function at six weeks with immobilisation, so early functional intervention may not necessarily be appropriate for more severe ankle injuries. 


\section{WHAT IS ALREADY KNOWN ON THIS TOPIC}

PRICE (protection, rest, ice, compression, and elevation) is commonly recommended in the acute management of ankle sprains

Few randomised controlled trials have studied the effectiveness of PRICE

\section{WHAT THIS STUDY ADDS}

Incorporating therapeutic exercises during the first week after ankle sprain resulted in significant improvements in short term ankle function compared with the standard PRICE intervention

This finding challenges popular advice on protection and rest for ankle sprains of minor and moderate severity
Ethical approval: This study was approved by the office of research ethics committee Northern Ireland.

Data sharing: No additional data available.

1 De Bie RA, de Vet HC, van den Wildenberg FA, Lenssen T, Knipschild PG. The prognosis of ankle sprains. Int J Sports Med 1997;18:285-9.

2 Bridgman SA, Clement D, Downing A, Walley G, Phair I, Maffulli N. Population based epidemiology of ankle sprains attending accident and emergency units in the West Midlands of England, and a survey of UK practice for severe ankle sprains. Emerg Med 2003;20:508-10.

3 Yeung MS, Chan KM, So CH, Yuan WY. An epidemiological survey on ankle sprain. Br J Sports Med 1994;28:112-6.

4 Braun BL. Effects of ankle sprain in a general clinic population 6-18 months after medical evaluation. Arch Fam Med 1999;8:143-8.

5 Anandacoomarasamy A, Barnsley L. Long term outcomes of inversion ankle injuries. Br / Sports Med 2005;39:e14.

Protection, rest, ice, compression, and elevation, the most popular current approach, is based largely on anecdotal evidence. The choice of mode, duration, and combination of the modalities within this approach are arbitrary, and many clinicians and departments fail to provide specific recommendations. Our study, with early controlled mobilisation and weight bearing, challenges popular advice on protection and rest.

\section{Conclusion}

We found evidence that incorporating therapeutic exercises during the first week after ankle sprain resulted in significant improvements in short term ankle function compared with a standard functional intervention. We also found evidence that the exercise group undertook significantly more weightbearing mobilisation during the first week after injury. The groups showed no other short or long term differences. The 16 week follow-up showed that both groups had high levels of ankle function, with just $4 \%$ of participants in each group having reinjury.

We thank Roisin Devlin, Martina Dunlop, and Michael Turner (emergency nurse practitioners, Royal Victoria Hospital, Belfast), and staff of the physiotherapy department at the Royal Victoria Hospital for their assistance with recruiting patients for the study.

Contributors: CMB wrote the original protocol, secured funding, assisted in the treatment intervention during the trial, wrote the final manuscript, and is the guarantor. SRO'C helped develop the protocol and was responsible for recruitment and treatment during the trial. MAT helped develop the protocol and was responsible for data handling during the trial. LGR was coprincipal investigator and was responsible for the overall management of the clinical setting in which the research took place. DCM helped write the original protocol and the final paper, and secured funding. SMD wrote the original protocol, secured funding, and was coprincipal investigator. IB and SM were responsible for data analysis; CMB, SRO'C, MAT, and SMD assisted with data analysis and interpretation of results. All authors contributed to and approved the final version of this manuscript.

Funding: This trial was funded by grants from the Physiotherapy Research Foundation and Strategic Priority Fund (Department of Employment and Learning, Northern Ireland). The researchers were independent of the funding agency.

Competing interests: All authors have completed the unified competing interest form at www.icmje.org/coi_disclosure.pdf (available on request from the corresponding author) and declare (1) no financial support for the submitted work from anyone other than their employer; (2) no financial relationships with commercial entities that might have an interest in the submitted work; (3) no spouses, partners, or children with relationships with commercial entities that might have an interest in the submitted work; and (4) no non-financial interests that may be relevant to the submitted work
6 Van Rijn RM, van Os AG, Bernsen RMD, Luijsterburg PA, Koes BW, Bierma-Zeinstra SMA. What is the clinical course of acute ankle sprains? A systematic literature review. Am J Med 2008;121:324-31.

7 Verhagen EA, van Tulder M, van der Beek AJ, Bouter LM, van Mechelen W. An economic evaluation of a proprioceptive balance board training programme for the prevention of ankle sprains in volleyball. Br/Sports Med 2005;39:111-5.

8 Cooke MW, Lamb SE, Marsh J, Dale J. A survey of current consultant practice of treatment of severe ankle sprains in emergency departments in the United Kingdom. Emerg Med/2003;20:505-7.

9 Lamb SE, Nakash RA, Withers EJ, Clark M, Marsh JL, Wilson S, et al. Collaborative Ankle Support Trial research team. Clinical and cost effectiveness of mechanical support for severe ankle sprains: design of a randomised controlled trial in the emergency department. BMC Musculoskelet Disord 2005;13:6:1.

10 Boyce SH, Quigley MA, Campbell S. Management of ankle sprains: a randomised controlled trial of the treatment of inversion injuries using an elastic support bandage or an Aircast ankle brace. $\mathrm{Br}$ J Sports Med 2005;39:91-6.

11 Beynnon BD, Renström PA, Haugh L, Uh BS, Barker H. A prospective, randomized clinical investigation of the treatment of first-time ankle sprains. Am J Sports Med 2006;34:1401-2.

12 See EK, Ng GY, Ng CO, Fung DTC. Running exercises improve the strength of a partially ruptured Achilles tendon. Br / Sports Med 2004;38:597-600

13 Järvinen TA, Järvinen TL, Kääriäinen M, Kalimo H, Järvinen M. Muscle injuries: biology and treatment. Am / Sports Med 2005;33:745-64.

14 Bring DK, Reno C, Renstrom P, Salo P, Hart DA, Ackermann PW. Joint immobilisation reduces the expression of sensory neuropeptide receptors and impairs healing after tendon rupture in a rat model. $J$ Orthop Res 2009;27:274-80.

15 Kerkhoffs GM, Rowe BH, Assendelft WJ, Kelly K, Struijs PA, van Dijk CN. Immobilisation and functional treatment for acute lateral ankle ligament injuries in adults. Cochrane Database Syst Rev 2002;(3):CD003762

16 Kerkhoffs GM, Struijs PA, Marti RK, Assendelft WJ, Blankevoort L, van Dijk CN. Different functional treatment strategies for acute lateral 2002;(3):CD002938

17 Kerkhoffs GM, Handoll HH, de Bie R, Rowe BH, Struijs PA. Surgical versus conservative treatment for acute injuries of the lateral ligament complex of the ankle in adults. Cochrane Database Syst Rev 2002;(3):CD000380.

18 Jones $\mathrm{MH}$, Amendola AS. Acute treatment of inversion ankle sprains: immobilization versus functional treatment. Clin Orthop Relat Res 2007;455:169-72.

19 Bleakley CM, McDonough SM, MacAuley DC. Some conservative strategies are effective when added to controlled mobilisation with Physiother 2008;54:7-20.

20 Perron M, Hébert LJ, McFadyen BJ, Belzile S, Regniére M. The ability of the Biodex Stability System to distinguish level of function in subjects with a second-degree ankle sprain. Clin Rehabil 2007;21:73-81.

21 Delahunt E, Monaghan K, Caulfield B. Changes in lower limb kinematics, kinetics, and muscle activity in subjects with functional instability of the ankle joint during a single leg drop jump. J Orthop Res 2006;24:1991-2000.

22 Delahunt E, Monaghan K, Caulfield B. Altered neuromuscular control and ankle joint kinematics during walking in subjects with functional instability of the ankle joint. Am / Sports Med 2006;34:1970-6.

23 Hall RC, Nyland J, Nitz AJ, Pinerola J, Johnson DL. Relationship between ankle invertor $\mathrm{H}$-reflexes and acute swelling induced by inversion ankle sprain. J Orthop Sports Phys Ther 1999;29:339-44.

24 Bleakley CM, O’Connor S, Tully MA, Rocke LG, MacAuley DC, McDonough SM. The PRICE study (Protection Rest Ice Compression ankle ligament injuries in adults. Cochrane Database Syst Rev external support after acute ankle sprain: a systematic review. Aust J 
Elevation): design of a randomised controlled trial comparing standard versus cryokinetic ice applications in the management of acute ankle sprain. BMC Musculoskelet Disord 2007;8:125.

25 Dijk van CN, Lim LSL, Bossuyt PMM, Marti RK. Physical examination is sufficient for the diagnosis of sprained ankles. J Bone Joint Surg [Br] 1996;78:958-62.

26 Steill IG, McKnight RD, Greenberg GH, McDowell I, Nair RC, Wells GA, et al. Implementation of the Ottawa ankle rules. JAMA 1994;271:827-32.

27 Bleakley CM, McDonough SM, MacAuley DC. Cryotherapy for acute ankle sprains: a randomised controlled study of two different icing protocols. Br J Sports Med 2006;40:700-5.

28 Knight KL. Cryotherapy in sports injury management. Human Kinetics, 1995.

29 Binkley JM, Stratford PW, Lott SA, Riddle DL. The Lower Extremity Functional Scale (LEFS): scale development, measurement properties, and clinical application. Phys Ther 1999;79:371-83.

30 Katz J, Melzack R. Measurement of pain. Surg Clin North Am 1999;79:231-52.

31 Rohner-Spengler M, Mannion AF, Babst R. Reliability and minimal detectable change for the figure-of-eight-20 method of measurement of ankle edema. J Orthop Sports Phys Ther 2007;37:199-205.

32 Grant PM, Ryan CG, Tigbe WW, Granat MH. The validation of a novel activity monitor in the measurement of posture and motion during everyday activities. Br J Sports Med 2006;40:992-7.

33 Williams GN, Molloy JM, DeBerardino TM, Arciero RA, Taylor DC Evaluation of the sports ankle rating system in young, athletic individuals with acute lateral ankle sprains. Foot Ankle Int 2003;24:274-83.

34 Karlsson J, Peterson L. Evaluation of ankle joint function. The use of a scoring scale. Foot 1991;1:15-9.

35 Rosner B. Fundamentals of biostatistics. 6th edn. Duxbury Press, 2000.

36 Ye Liang K, Zeger SL. Longitudinal data analysis of continuous and discrete responses for pre-post designs. Indian I Stat 2000;62:134-48.

37 Begg C, Cho M, Eastwood S, Horton R, Moher D, Olkin I, et al Improving the quality of reporting of randomized controlled trials. The CONSORT statement. JAMA 1996;276:637-9.

38 Hubbard TJ, Kaminski TW. Kinesthesia is not affected by functional ankle instability status. J Athl Train 2002;37:481-6.
39 Watts BL, Armstrong B. A randomised controlled trial to determine the effectiveness of double Tubigrip in grade 1 and 2 (mild to moderate) ankle sprains. Emerg Med / 2001;18:46-50.

40 Freeman MA, Dean MR, Hanham IW. The etiology and prevention of functional instability of the foot. J Bone Joint Surg $\mathrm{Br}$ 1965;47:678-85.

41 Konradsen L, Olesen S, Hansen HM. Ankle sensorimotor control and eversion strength after acute inversion injuries. Am J Sports Med 1998;26:72-7.

42 Wester JU, Jespersen SM, Nielsen KD, Neumann L. Wobble board training after partial sprains of the lateral ligaments of the ankle: $a$ prospective randomised study. J Orthop Sports Phys Ther 1996;23:332-6

43 Holme E, Magnusson SP, Becher K, Bieler K, Bieler T, Aagaard P, et al. The effect of supervised rehabilitation on strength, postural sway, position sense and re-injury risk after acute ankle sprain. Scand I Med Sci Sports 1999;9:104-9.

44 Hopkins JT, Ingersoll CD, Krause BA, Edwards JE, Cordova ML. Effect of knee joint effusion on quadriceps and soleus motoneuron pool excitability. Med Sci Sports Exerc 2001;33:123-6.

45 Palmieri-Smith RM, Hopkins JT, Brown TN. Peroneal activation deficits in persons with functional ankle instability. Am J Sports Med 2009;37:982-8.

46 Palmieri RM, Ingersoll CD, Hoffman MA, Cordova ML, Porter DA, Edwards JE, et al. Arthrogenic muscle response to a simulated ankle joint effusion. Br J Sports Med 2004;38:26-30.

47 Hopkins JT, Palmieri R. Effects of ankle joint effusion on lower leg function. Clin J Sport Med 2004;14:1-7.

48 Akbari M, Karimi H, Farahini H, Faghihzadeh S. Balance problems after unilateral lateral ankle sprains. J Rehabil Res Dev 2006;43:819-24.

49 Cooke MW, Marsh JL, Clark M, Nakash R, Jarvis RM, Hutton JL, et al. Treatment of severe ankle sprain: a pragmatic randomised controlled trial comparing the clinical effectiveness and cost-effectiveness of three types of mechanical ankle support with tubular bandage. The CAST trial. Health Technol Assess 2009;13:1-121.

50 Lamb SE, Marsh JL, Hutton JL, Nakash R, Cooke MW, Collaborative Ankle Support Trial (CAST Group). Mechanical supports for acute, severe ankle sprain: a pragmatic, multicentre, randomised controlled trial. Lancet 2009;373:575-81.

Accepted: 16 February 2010 